Results The analysis showed that there was an ICER (Incremental Cost-Effectiveness Ratio) of 32000 GBP/OALY (Quality Adjusted Life Years) associated with high dose dry powder FP/S 1000/100 $\mu \mathrm{g}$ vs extrafine BDP/F 400/24 $\mu \mathrm{g}$ and an ICER of approximately 36800 GBP/OALY associated with medium dose dry powder FP/S 500/ $100 \mu \mathrm{g} v \mathrm{~s}$ BDP/F 400/24 $\mu \mathrm{g}$. Additional analysis showed that there was an ICER of 85200 GBP/OALY associated with high dose suspension formulation $\mathrm{FP} / \mathrm{S}$ 1000/100 $\mu \mathrm{g}$ vs extrafine BDP/F 400/ $24 \mu \mathrm{g}$.

Conclusions BTS/SIGN guideline recommend that when asthma control is achieved, treatment can be stepped down to the lowest dose that maintains control. It was found that maintaining controlled patients on high dose FP/S is not cost-effective. Extrafine $\mathrm{BDP} / \mathrm{F} 400 / 24 \mu \mathrm{g}$ daily can be considered to be a cost-effective option in the UK to maintain control of asthmatic patients stepped down from high dose $\mathrm{FP} / \mathrm{S} 1000 / 100 \mu \mathrm{g}$ daily dry powder or suspension formulations and the magnitude of cost effectiveness is estimated to be highest when stepping down from the suspension formulation.

\section{P114 DIFFICULT ASTHMA: THE PLYMOUTH EXPERIENCE}

doi:10.1136/thoraxjnl-2011-201054c.114

B Castell, D Pike, M Masoli. Plymouth Hospitals NHS Trust, Plymouth, Devon

Introduction Difficult asthma represents a significant unmet clinical need and burden on healthcare resources. We recently set up a difficult asthma clinic (DAC) in Plymouth and conducted an observational study of our experience to date.

Methods The DAC started in April 2010 evaluating patients using a systematic multidisciplinary approach. Patients were symptomatic at $=$ Step 4 BTS guidelines and arose from a combination of cross referrals, inherited patients and asthmatics under regular chest clinic follow-up.

Results 113 patients were evaluated within the DAC. 74 women. Mean age 48 yrs. 15 patients were felt either not to have asthma or asthma was not the primary diagnosis. Diagnoses included bronchiectasis (3), Goitre (1), obliterative bronchiolitis (1), tracheal involvement from ulcerative colitis (1), chronic pulmonary emboli (1), Churg-Strauss syndrome (1). 98 patients had difficult asthma. 14 patients had an occupational element, three with reactive airways dysfunction syndrome. 72 had comorbidities which included: vocal cord dysfunction/dysfunctional breathing (19), bronchiectasis (20), Class II Obesity (19), COPD/emphysema (9), GORD (31), immune deficiency (5), OSA (5), psychological (11), allergic bronchopulmonary aspergillosis (2). Medication at baseline: 46 patients were on long term oral corticosteroids (OCS) (mean $22 \mathrm{mg} / \mathrm{d}$ ). Most patients were able to significantly reduce their OCS dose, mean reduction $53 \%$. 12 were able to discontinue OCS entirely. Mean inhaled corticosteroid dose $2287 \mathrm{mcg} / \mathrm{d}$ (BDP equivalent). Subcutaneous terbutaline (3), cyclosporin (2), Anti-IgE therapy (1). Currently seven on anti-IgE therapy. 58 had severe refractory asthma by American Thoracic Society criteria. Mean IgE $531 \mathrm{kU} / \mathrm{l}$, mean FeNO $40.5 \mathrm{ppb} .15 / 58$ had fungal sensitivity. Adherence: 1 of 12 patients tested was identified as non-adherent with undetectable prednisolone level and normal cortisol. Healthcare utilisation: 68 patients with 12 months follow-up data demonstrated a significant reduction in hospitalisations compared to the previous 12 months, 1.00 vs 0.53 .

Conclusion This study highlights the importance of alternative diagnoses and comorbidities in the work up of difficult asthma. IgE and FeNO were higher than expected as was adherence to OCS compared to published studies. The implementation of a DAC has reduced hospital admissions, reduced OCS requirement and enhanced access to treatments such as Anti-IgE therapy.

\section{Cellular responses in the aetiology of COPD P115 CHRONIC DIESEL EXHAUST PARTICLE (DEP) EXPOSURE DIFFERENTIALLY ALTERS MONOCYTE DIFFERENTIATION AND FUNCTION IN HEALTHY CONTROLS COMPARED TO COPD}

doi:10.1136/thoraxjnl-2011-201054c.115

${ }^{1} \mathrm{~N}$ Chaudhuri, ${ }^{2} \mathrm{H}$ Jary, ${ }^{3} \mathrm{~S}$ Lea, ${ }^{3} \mathrm{~N}$ Khan, ${ }^{1} \mathrm{~L} \mathrm{C}$ Parker, ${ }^{3} \mathrm{D}$ Singh, ${ }^{1} \mathrm{I}$ Sabroe. ${ }^{1}$ Academic Unit of Respiratory Medicine, University of Sheffield, Sheffield, UK; ${ }^{2}$ Academic Unit of Respiratory Medicine, The University of Newcastle, Newcastle, UK; ${ }^{3}$ Respiratory Medicine Research Group, University of Manchester, Manchester, UK

Introduction and Objectives Alveolar macrophages are heavily implicated in the pathogenesis COPD. During chronic inflammation, macrophages mature continuously from infiltrating monocytes that are continually recruited to the airways. We have previously found DEP modulate life span and function of monocytes from healthy donors, but their effects on monocytes of people with COPD are unknown, and were therefore the subject of this study.

Methods Monocytes were purified from the blood of patients with GOLD II/III COPD and healthy age matched controls Monocytederived macrophages (MDMs) were generated in the presence or absence of DEP and their lifespan studied. Cytokine generation in response to TLR agonists and heat killed bacteria was assessed by ELISA and expression of CD14 was measured by FACS.

Results Chronic exposure of monocytes from patients with COPD to DEP concentrations above $10 \mu \mathrm{g} / \mathrm{ml}$ caused a significant reduction in cell survival. Lower concentration of chronic DEP exposure, as low as $1 \mu \mathrm{g} / \mathrm{ml}$, caused impairment of cytokine responses to LPS and heat killed Escherichia Coli, and this phenotype was associated with a reduction in CD14 surface marker expression. However, COPD monocytes were generally more resistant to the effects of DEP compared to healthy control cells.

Conclusions In this study monocytes from healthy volunteers appeared to be more susceptible to the harmful effects of chronic DEP exposure compared to those from individuals with COPD. These findings reinforce the evidence that circulating leukocytes in COPD patients have altered phenotypes.

\section{P116 TESTING ANTIOXIDANT AND ANTI-INFLAMMATORY THERAPIES IN A COMPLEX LUNG TISSUE MODEL}

doi:10.1136/thoraxjnl-2011-201054c.116

T S Singh, F R Razali, M N North, T W Wilkinson, B L N Nicholas. University of Southampton, School of medicine, Southampton, UK

COPD is a disease of global importance and its primary cause airway inflammation as a consequence of cigarette smoking is well described. However, there remains a lack ofeffective therapies for this important condition. Animal models of disease are limited in their predictive utility and therefore creation of a complex, human disease modelis an important step for testing new therapeutic interventions. We therefore established a tissue model of oxidative and inflammatory responses to relevant triggers-cigarette smoke and LPS and determined the impact of interventions in the optimised system.

Methods Human lung tissueexplants from the resected lobes of six consented patients undergoing lobectomy were used. Uniform tissue explants were established on a novel culture system and then treated with CSE and LPS before the supernatants were collected optimal dosing was determined. Treatments and control experiments were performed with the anti-oxidant Vitamin $\mathrm{C}$ and fluticasone. Inflammatory readouts were measured by ELISA; TNFa, IL-8 and MMP-9. 
Results Lung tissue treated with CSE showed a dose-dependent increase in IL-8 and MMP-9 secretion across a range $0.6250 \%-20 \%$ CSE. IL-8 response to 20\% CSE was $71592.21 \mathrm{pg} / \mathrm{mg} / \mathrm{ml} \pm 4680.7 \mathrm{SE}$ compared to non-stimulated tissue $14177 \mathrm{pg} / \mathrm{mg} / \mathrm{ml} \pm 1088 \mathrm{SE}$ ( $\mathrm{n}=6, \mathrm{p}<0.001$ ), MMP-9 response to $20 \%$ CSE $206 \mathrm{pg} / \mathrm{mg} / \mathrm{ml}$ $\pm 30.55 \mathrm{SE}$ vs control $104 \mathrm{pg} / \mathrm{mg} / \mathrm{ml} \pm 4.49 \mathrm{SE}$ ( $\mathrm{n}=6, \mathrm{p}<0.001$ ). However no demonstrable rise in TNF- $\alpha$ secretion from tissue treatedwith CSE was detectable. With LPS stimulation both TNF- $\alpha$ and IL-8 responses demonstrated adose-dependent increase within the range $0.01-100 \mathrm{ng} / \mathrm{ml}(\mathrm{n}=5, \mathrm{p}=0.0003)$.

Treatment effects Stimulated IL-8 and MMP-9 secretion was significantly reduced in tissue treated with $0.1 \%$ vitamin C. $25 \%$ reduction in IL8 $(n=3, p=0.065)$ and $32 \%$ reduction in MMP9 $(n=3$, $p=0.0133$ ). Fluticasone treatment reduced LPS induced TNF- $\alpha$ and IL-8 in a dose dependent manner $(n=4, p=0.03)$.

Conclusions A human lung tissue model of smoke and LPS induced inflammation demonstrates the importance of selecting appropriate readouts for a given stimulus or treatment and hence a potential utility in selecting trial endpoints. Furthermore it demonstrates that vitamin $\mathrm{C}$ and corticosteroids can reduce oxidative stress and inflammation in a complex tissue system- their combined effects warrant investigation in COPD.

\section{P117 3D CRYO-ELECTRON MICROSCOPIC ANALYSIS OF THE DISEASE MECHANISM OF $\alpha 1$-ANTITRYPSIN DEFICIENCY}

doi:10.1136/thoraxjnl-2011-201054c.117

${ }^{1} B$ Gooptu, ${ }^{1} Y$ Chaban, ${ }^{2} \mathrm{~J}$ A Irving, ${ }^{1} \mathrm{D}$ K Clare, ${ }^{2} \mathrm{D}$ A Lomas, ${ }^{1} \mathrm{E}$ Orlova, ${ }^{1} \mathrm{H}$ R Saibil. ${ }^{1}$ Institute of Structural and Molecular Biology, Department of Biological Sciences, Birkbeck College, University of London, London, UK; ${ }^{2}$ Department of Medicine, University of Cambridge, Cambridge Institute for Medical Research, Cambridge, UK

$\alpha_{1}$-antitrypsin deficiency is characterised by predispositions to liver disease and severe, early-onset emphysema. It is caused by point mutations that destabilise the molecular structure of $\alpha_{1}$-antitrypsin, leading it to self-associate into chains known as polymers. Polymerisation abolishes the antiprotease activity of $\alpha_{1}$-antitrypsin and causes circulating deficiency of the protein. These loss-of-function effects result in dysregulated elastase activity within the lung parenchyma. In addition, polymerisation has pro-inflammatory gain-of-function effects that must be mediated through the structural characteristics of the polymer itself. It is therefore important to understand the structure of the $\alpha_{1}$-antitrypsin polymer to identify targets for drug design. We have used cryo-electron microscopy, single particle reconstruction techniques to study $\alpha_{1}$-antitrypsin polymers. Analysis of the 3D arrangement of $\alpha_{1}$-antitrypsin molecules within the directly observed polymer chain allows us to evaluate current competing models of polymer assembly.

\section{P118 THE ROLE OF THE RETINOIC ACID PATHWAY IN HUMAN LUNG REGENERATION}

doi:10.1136/thoraxjnl-2011-201054c.118

J P Ng-Blichfeldt, M Griffiths, U Griesenbach, B Allen, M Hind. Imperial College London, London, UK

Recent studies into retinoic acid (RA)-induced alveolar regeneration in rodent models of emphysema and bronchopulmonary dyplasia strongly suggest a latent regenerative potential of the adult mammalian lung. RA signalling is known to have an important role during alveolar formation in the developing lung in rodents and man. However, critical differences between animal and human physiology and development qualify the relevance of animal models of regeneration. Here we explore the role of RA signalling in human lung regeneration. Using RT-PCR with primers specific to RA signalling genes, we confirm expression of the RA synthesising enzymes Raldh1, 2 and 3, RA degrading enzymes Cyp26 A1, B1 and $\mathrm{C} 1$, retinoic acid receptors RAR- $\alpha, \beta, \gamma$ and retinoid binding proteins CRBPI and II, and CRABP I and II in normal, human peripheral lung tissue. To determine which cell types of peripheral lung are involved in RA signalling we have isolated primary alveolar type 2 epithelial cells and primary vascular endothelial cells and confirm expression of RA signalling genes. We have developed an high performance liquid chromatography (HPLC) method to identify and quantify endogenous human lung retinoids and demonstrate the ability to separate known standard retinoids by characteristic elution times. Finally, using precision cut lung slices we are developing an experimental system to determine the effects of retinoids in an architecturally complex human tissue model. Future work will include characterisation and optimisation of a primary human type 2 alveolar epithelial cell wound healing model and the effects of various selective retinoic acid receptor agonists and antagonists.

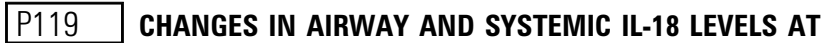 EXACERBATION IN COPD PATIENTS}

doi:10.1136/thoraxjnl-2011-201054c.119

A J Mackay, G C Donaldson, A R C Patel, R Singh, J R Hurst, J A Wedzicha. Academic Unit of Respiratory Medicine, UCL, London, UK

Introduction IL-18 is a proinflammatory cytokine implicated in COPD pathophysiology, causing pulmonary inflammation and emphysema in murine models. IL-18 receptor expression is increased on alveolar macrophages in COPD. ${ }^{1}$ IL-18 levels are elevated in serum and sputum of stable COPD patients. We hypothesised that airway and systemic IL-18 concentrations increase further at exacerbation.

Methods Sputa and sera prospectively collected from the London COPD cohort were analysed using ELISA (eBioscience ${ }^{\circledR}$, Vienna). Patients had an $\mathrm{FEV}_{1}=80 \%$ predicted and $\mathrm{FEV}_{1} / \mathrm{FVC}$ ratio $=0.7$. Baseline was defined as at least 6 weeks after, and 2 weeks before, an exacerbation. An exacerbation was defined as an increase for two consecutive days in respiratory symptoms, with at least one major symptom (dyspnoea, sputum purulence or volume) plus another major or minor (wheeze, cold, sore throat or cough) symptom. Exacerbation frequency was calculated from daily diary cards collected over the previous 12 months. When unavailable, patient's recall of exacerbations over the preceding year was used. Frequent exacerbators had $\geq 2$ exacerbations in the preceding year, infrequent exacerbators $<2$

Results 94 COPD patients had serum analysed, of whom 48 also had sputum analysed. $60 \%$ were male, mean age was 71.6 years (SD 8.5), mean $\mathrm{FEV}_{1}$ predicted $50.6 \%$ (18.1). Sputum IL-18 levels increased significantly from baseline to exacerbation (median 1.46 $\log _{10} \mathrm{pg} / \mathrm{ml}$ (IOR 0.96-2.01) vs 1.95 (0.96-2.23), $\mathrm{n}=48, \mathrm{p}=0.023$, Abstract P119 figure 1). However, serum IL-18 concentrations were not significantly greater at exacerbation compared to paired baseline levels (median $2.17 \log _{10} \mathrm{pg} / \mathrm{ml}(1.97-2.37$ ) vs 2.08 (1.91-2.36), $\mathrm{n}=31, \mathrm{p}=0.299)$. There was no correlation between baseline serum IL-18 concentrations and exacerbation frequency $(n=94, \rho=0.096$, $\mathrm{p}=0.357$ ) or $\mathrm{FEV}_{1} \%$ predicted ( $\left.\mathrm{n}=93, \rho=0.081, \mathrm{p}=0.443\right)$. No significant difference was found in baseline serum IL-18 concentrations between frequent and infrequent exacerbators (median $148 \mathrm{pg} / \mathrm{ml}(95-235 ; \mathrm{n}=46)$ vs 120 (78-219; $\mathrm{n}=48), \mathrm{p}=0.431)$. There was no correlation between baseline serum IL-18 concentrations and paired sputum levels $(n=42, \rho=-0.149, p=0.348)$.

Conclusions Sputum but not serum IL-18 increases at COPD exacerbation. Treatment options for exacerbations are limited and there is a need for novel anti-inflammatories. The results of this study suggest IL-18 as a potential target for exacerbation therapy. 